\title{
LA ALIMENTACION ARTIFICIAL DE LOS LACTANTES INTERNADOS EN LA CASA DE EXPOSITOS DE BUENOS AIRES
}

\author{
Por fos Dres. PEDRo DE ELIzALDE y ADOLFo GIUSSANI. \\ Bumos Aires. Argentiza.
}

En la presente nota, como contribución al Tema I de este Congreso, deseamos dar una idea de la forma cómo se íace la alimentación artificial de los niños de pecho, interriados en la Casa de Expósitos de Buenos Aires.

Naturaleza de la institución y clase de lactantes que alli se internan. - Por sus finalidades debe irternarse indistinta. mente a lactantes enfermos o sanos. Habitulimente ocupan cunas en sus diversos servicios alrededor de 150 a 170 lactantes cuya alimentación se trata de realizar a base de mujer.

Cuenta la institución para ese objeto con nodrizas internas cuyo número debiera ser 80 , pero que nunca está cuhierto por falta de aspirantes y con un servicio de extracción de leche de mujer que suministra entre 25 y 30 litros diarios da este alimento.

Como eso no basta para poder llevar a cabo la alimentación exclusiva con leche de mujer y como, por otra parte, no siempre hay contra indicaciones para otro género de alirentación, se recurre con frecuencia a la alimentación artíicial, usándola, según los casos, en forma exclusiva o compiementando la lactancia natural insulficiente.

Circunstancias que autorizan la alimentación mixta o attificial.-Hace algunos años, cuando un congreso interno de la Asociación Méóica Argentina, se ocupó de los factores que irfluyen en el resultado de la alimentación artificial del lactante, frente a otras opiniones, uno de nosotros (Elizalde) marifestó que, a su entender, en igualdad de circunstancias, la alimentación artificial practicada en la vivienda obrera tenía mencs riesgo que la practicada en nuestros hospitales $e$ institutos. . 
Fundaba este modo de ver en su experiencia en la Casa de Expósitos, donde había visto lo difícil que, aún con alimento natural, era hacer prosperar a los niños internados.

Hoy, con un perfeccionamiento indiscutible en los métodos de cuidado, sigue siendo todavia muy difícil el llevat a feliz término la alimentación de esos niños; pero es evidente que cada día se van mejorando los resultados.

En la Casa de Expósitos se llega a la alimentación mixta o artíficial, eligiendo los niños que podrán soportarla con menores inconvenientes.

Desde luego, cierto número de lactantes ingresa con el antecedente de haber estado sometido a una alimentación attificial más o menos bien tolerada. No hay inconveniente en alimentar a estos niños en la misma forma que se alimentaban antes de ingresar.

Otro grupo de niños está en condiciones de pocier ser despechaco, sea por su edad. sea porque su estado de eutrofia hace suponer que alimentación mixta y artificial será bien tolerada. Existen además, otros niños en los que, por su estado di distrofia la alimentación artificial resulta un complemento s'guramente recesario para cubrir los requerimientos nutritivos.

Para llevar a cabo la alimentación mixta o artificial, cada niño es estudiado individualmente, tratando de establecer el régimen más adecuado a sus condiciones, de acuerdo con los resultados que se van obteniendo en la observación diaria. No hay, por consiguiente, tipos fijos y permanentes de alimentación; ésta varia con frecuencia mientras se està estudiando al niño, y luego de establecidas las raciones óptimas en calidad y cantidad, cuando ya el niño está en posición normal, tiene que variar ó nuevo por la necesidad de adaptar 2) régimen a las posibilidades que al darlo de alta se tendrán para alimentarlo, en el domicilio de su familia o de sus cuicadores.

La preparación de alimentos.-Deben prepararse diariamente alređedor de 700 frascos de la más vatiada composición. Con este fin se ba ido organizando el Laboratorio de Alimentación, con el criterio de simplificat al máximo sus tareas tratando de ponerlo de acuerdo a las condiciones particulares del Establecimiento.

Instalación.-E1 Labotatorio se ha instalado con la menor cantidad posible de aparatos complicacos o costosos, partiendo del concepto que, ctianto más simple sea su instalación. tanto más fácil y económico resultaxạ hacerlo funcionar. 
Tipo de trabajo.-Calcado del trabajo doméstico. Cada niño tiene su frasco marcado con su número, el que sólo sê usa para él. Los frascos se esterilizan al autoclave una vez al día, se lavan a mano en agua fría inmediatamente cespués de haberlos usado $\mathrm{y}$ se lavan de nuevo en agua caliente antes de volverlos a llenar, en el mismo momento en que se van a adriinistrar. No se esterilizan ni se guarda ninguna mamader? ya lista para el uso. Lo que no se utiliza en seguida de praparado se considera sobrante $y$ se dedica a otros fines que la alimentación de los niños. Los frascos se entregan a las Salas herméticamente cerrados, con el contenido justo que el niño a que está destinado deberá consumir. Como van calientes a $60^{\circ}$ a fin de que lleguen a destino con temperatura adecuada para ser administrados, fa cuidadora no tiene otro trabajo que destaparlos y ponerles la tetina que es personal para cada niño y mantiene bien limpia en un vaso de agua hervida. Está prohibido todo trasvase y cambio de frascos en las Salas.

Personal.-Un Médico Jefe, 1 preparadora y 4 ayudantas.

Horarios.--En una Institución tan complícada como la Casa de Expósitos, resulta muy difícil establecer horarios particulares, en los distintos Servicios es necesario coordinarlos aun sacrificando muchas veces pequeñas necesidades. Por este notivo no se puede sino, gor excepción, establecer horarios de alimentacion propios a cada niño. La casi totalidad de los lactantes deben alimentarse cada 3 horas. dentro ce un horar:o general. calculado como el más adecuado para que no se ertorpezcan entre sí las actividades de los distintos Servicios. Se reconoce. sin embargo, que serian de desear pausas más largas entre un alimento y otro, pero no se ha conseguido liegar a la implantación de un sistema que resuelva este punto.

Sólo toman alimento durante la noche los niños que no se adaptan a la pausa de 9 horas, que va.de la última a la primera alimentación de horatio.

Raciones.-Los requerimientos son explorados en cada niño hasta llegar a establecer la ración óptima. Nuestra experiencia es que nuestros niños tienen exigencias globiles muy superiores a las que se indica como normales, tanto en $\mathrm{el}$ ex. tranjero como en el pais. Si en éste se trara de una condición derivada de modalidades propias a la institución, del género de vida que allí llevan los niños, no podemos afirmarlo. Lo cierto es que con mezclas alimenticias equilibradas, tanto en alimentación mixta como artificial, con bastante frecuencia necesitamos llegar a raciones hídricas y calóricas altas. supe- 
riores muchas veces a 140 calorías por kilo en niños eutróficos del $2 \because$ semestre.

Por esta circunstancia, los alimentos que más se emplean. án los de alto valer calórico.

Materias primas empleadas en la preparación de alimemos. - Se ha restringido al mínimum el uso de alimentos industriales, ya preparados. La industria privada ha llegado "A Buenos Aires a un grado de perfección satisfactorio en todo santido; además de un sinnúmero de alimentos de serie es hicil obtener muy bien preparada cualquier mezcla que se dese para indicaciones especiales. Pero el costo de estos alimenlos es elevado. Dentro de una igualdad de calidaces las instiuriones oficiales están obligadas a buscar la forma de adquix.ión más económica.

Poco a poco la Casa de Expósitos tha conseguido prescindir casi por completo de esos preparados industriales caris. i produce a precios mínimos, partiendo de materias premas bien seleccionadas, alímentos básicos para con ellos comiuner las distintas combinaciones dietéticas de uso propio.

Leche de vaca, - Se atiliza para las preparaciones láci. as una leche que no está en el comercio, obtenida a precio juy bajo por gentileza de una de las principales empresas intheras del país.

Proviene de un tambo de vacas de raza holando-argentina. elegidas, tuberculinizadas, cuidadas a campo y ordeñadas con limpieza. Esta leche se enfría inmediatamente después de! odeñe, y se remite cruda, en tarros certados. Llega a la hehidera del Laboratorio entre las tres y cuatro de la mañana. antes de haber transcurrido 12 horas del ordeñe $y$ se consume ('ii) el curso del día.

Esta leche tiene una cantidad de manteca que está cast vimpre alrededor de $3.5 \%$; a menudo llega y pasa del $4 \%$. Su pureza es grande, su gusto agradable y el contenido en grinenes muy bajo. Se guarda en la heladera a 4" hasta el incmento en que se la va a utilizar.

Después de muchos ensayos hemos encontrado que la fornti más simple y más rápicia de calentar la leche es la inycción de vapor de agua sobre-calentado. siguiendo el sistema que se usa en los bares y restaurants. En 4 minutos, inyectando un chorro de vapor a la presión de 62 libras se obtienc la ebullición de 9 litros de leche fría a $5^{\circ}$. Esa misma rncidad de leche calentada en ollas con una potente fuente se calor, necesita para hervit de 35 a 45 minuros. 
La ebullición por medio del chorro ãe vayor diluye la leche en un $10 \%$, 10 que debe tenerse en cuenta para parar con dilución precisa las distintas mezclas lácteas. En cambio con ella no se forman natas que pueden hacer perder hasta un $40 \%$ de la manteca de la leche.

El ácido ascórbico, según dosajes que hemos hecho practicar, casi no se modifica con el calentamiento rápido del chorro de vapor.

Derivados de la leche.--Sólo por excepción se utilizan polvos de leche. Sin embargo no cabe duda que en ciertos casos se toleran mejor las leches reconstituidas que las leches frescas. De ahi que no se haya abandonado su nso por completo. Lo mismo ocurre con la leche condensada que es de beneficios indiscutibles en algunos casos de vómitos y en ciertas detenciones del aumento de peso. Para el empleo en estos úitimos casos, preparamos una leche hiperazucarada con que substituímos a las diluciones habituales de leche condensada.

Leches acidulatas. - Se usan abundantemente tanto las descremadas, las íntegras o las hipergtasosas. Estas leches aciduladas con ácido láctico o jugo de limón substituyen a las leches ácidas por fermentación, a la leche hipergrasosa de Gaing $y$ al babeurre.

Una de las preparaciones que más se emplea es la que designamos como Tipo 3 , equivalente a la leche de Marriott.

Harinas.-Además de todas las barinas simples que entran en las óistintas preparaciones de uso corriente, prepara. mos distintos tipos de mezclas de harinas tostadas. En selecciones sucesivas hemos elegido dos de estas mezclas, las que llamamos Tipos $\mathrm{K}$ y S, por su sabor agradable, ya que por sus otras cualidades dietéticas son equivalentes.

Con estas harinas que calentamos en un horno giratorio, para tener un tostado uniforme, sustituimos a las preparaciones de ámido dextrina que en gran número procuce la industria, disminuyendo su costo a la décima parte.

Hemos traído una muestra de una de ellas, la Tipo K. para empleo como ensayo en alguna clínica. Nos cuesta a nosotros $\$ 0.50$ el kilo, siendo así que el producto similar importado, costaba en Buenos Aires, antes de la guerra, $\$ 5$ et kilo.

Jarabe de dextrino maltosa.-Oiro componente básico que utilizamos para la preparación de distintas mezclas es un jarabe de dextrino maliosa, cuya composición. según análisis repetidos que muestran pocas variaciones, es la siguiente: dextrina, $23 \%$; maltosa, $23 \%$; glucosa, $4 \%$. 
Este jarabe se prepara haciendo actuar extracto de malta sobre engrudo de efécula de papas hasta completa desaparición del almidón. Luego se concentra por ebullición. Equivale a una solución al $50 \%$ de los preparados comunes industriales de dextrino maltosa en polvo, que dicho sea de paso, no tienen siempre la exacta composicion que marcan los prospectos.

Pata facilitar el trabajo de las preparadoras se bacen con anticipación scluciones madres de todos los componentes (sacarosa en leche a distintas concentraciones, cocimientos de $\mathrm{ce}^{-}$ reales y de harinas simples ó transformadas, etc.), de manera que en el momento de preparat los frascos se pueden hacer icda clase de mamaderas usando solamente medidas de volumen, de empleo mucho más expeditivo que las de peso. De esa manera trabajando 4 ayudantas se puede terminar en menos de una hora la preparación de cada remesa que excede de $j 00$ mamaderas de composición y de proporciones distintas.

Petitorto. - El Laboratorio de Alimentación proporciona cualquier clase de alimento que puedan indicat los médicos tratantes. No se limita en forma alguna sus ptescripciones; pueden, si lo desean, usar como ensayo o porque lo crean más conveniente las especialidades del comercio, pero prefietien generalmente los alimentos provenientes del Laboratorio, tanto para la práctica diaria como cuando se proponen estudiar aígún punto particular de dietética.

Pata allanar dificultades innecesarias en el trabajo, se ha establecido un petitorio de preparaciones standard que son las gue se usan con frecuencia. Acompañamos en hoja aparte este petitorio.

Lamentamos haber detenido la atención de los oyentes con un aspecto tan árido del problema de la alimentación del lactante, pero creemos que cuando más se reajusten los sistemas de provisión de alimentos, tanto menos dificultades se tendrá para el cuidado de los lactantes.

Quiene hemos trabajado en instituciones de asistencia en épocas en que no se daba a este punto la atención que se requiere recordamos bien el desastre que era la alimentación artificial. a tal punto, que en algunas de tales instituciones eslaba proscrita y sólo se empleaba la alimentación por medio de nodrizas.

Si hemos entrado en minacias ha sido en mérito a la imFortancia que atribuimos al régimen de organización y de trabajos de las cocinas dietéticas para lactantes. 
No vamos a extendernos estudiando los resultados obtenidos con la alimentación artificial, practicada en la forma que acabamos de referir. Hemos dicho anteriormente que tenemos la impresión de que hemos mejorado mucho en Jos. últimos años, pero nos llevaría inuy lejos analizar en detalle esos resultados.

Atribuimos la mejora al hecho de haber encarado en cada caso el problema de la alimentación artificial en todos sus aspectos, considerando no sólo el alimento en si mismo. sino a su forma de administración y su adecuación a las necesidades del niño y a su modalidad constitucional. Hemos dado también gran valor a los factores externos, de ambiente $y$ de cuidado que caracterizan las instituciones de asistencia cerradas. Al corregir las faltas, que fuimos encontrando en la medida de nuestras posibilidades, se consiguió un mayor reajuste de la técnica del cuidado y de la forma de alimentación, factores que en conjunto rigen la alimentación del lactante tanto sano como enfermo.

Leche amido dextrino mallosada. Tipo modificado o Tipo 1.-Se cocina a fuego lento durante 10 minutos 30 gramos de hatina de atroz en 600 gramos de agua. Se le agregan 200 gramos de jarabe de dextrino maltosa y 300 gra. nios de leche hervida. E1 todo debe resultar I litro.

Calorías por litro: 720 .

Cocimiento de harina dextrino maltosada. Tipo M.Para cada 100 gramos de cocimiento típo S, al $10 \%$ se le agregan 3 gramos de extracto de malta a 70 grados; se hace hervir.

Calorías por litro: 400 .

Jarabe de Dextrino Maltosa.-Para reemplazar al Dextro Malt.-Se diluyen 2 kilos de 'écula dz papas en 12 litros de agua, se hierve durante 5 minutos. Se enfría hasta 60 grados y se le agregan 50 gramos a 100 gramos de Extracto de Malta y se deja actuar basta desaparición de la reacción dei a!midón con la solución yodo yodurada o con la tintura de yodo. (Comenzar a observar a los 10 minutos y repetir la reacción cada tres minutos). Cuando desaparece la reacción. hervir, se cuela caliente y se concentra con ebullición hasta 3 litros y 200 gramos.

Calorías por litro: 2,000 .

Leche hiperazucarada.-A 1 litro de leche se le a'grega 500 gramos de agua y 120 gramos de azúcar. Se lleva a 80 grados y se mantiene a esta temperatura durante 1 hora, revol. 
viendo continuamente. Se enfría. Sustituye a la leche condensada en dilución al $23 \%$.

Calorías: $76 \%$.

Harinas dextrinadas.

Tostado de las harinas.- Se coloca en la mezcladora harina en cantidad tal que cubra, por lo menos, la aleta inferior y no exceda de la mitad del espacio que separa las dos aletas. Llevar la temperatura del horno a 240 grados; cuando comienza a salir humo, apagar el fuego y dejarla en el horno aún 6 minutos para la harina de trigo, 5 minutos para la ceEada y 4 para la ce centeno (más o menos). Vigilar para Gue el tostado no exceda del color crema claro.

Harina Tipo S. -2 partes de harina de trigo y 1 parte de harina de cebada. Tostadas previamente.

Harina Tipo $K,-2$ partes de hatina de trigo, 1 de harina de cebada y $11 / 2$ de harina de centeno, previamente tostadas.

\section{Leches aciduladas.}

Leche ínlegra acidulada.-Se hierve la leche al vapor, se enfría y se le agrega agitando continuamente, $3,5 \mathrm{cc}$. de ácido láctico por litro, ó 25 a 50 gramos de jugo de limón. (Agregar hasta que se corte y se notará por el espesamiento). Si la cantidad de leche para acidular es menor, contar 10 a 14 gotas por 100 gramos de leche.

Calorias: 620 por litro.

Leche semidescremada acidulada. (Sustituye al babeurte). - Se prepara mezclando 2 litros de leche desnatada y 1 litro de leche integra. Se hierve, se enfría y aridula.

Calorías: 500 por litro.

Leche descremada acidulada,-Se acidula la leche hervida tal como se obtiene de la desnatadora.

Calorías: 300 por litros.

Leche hipergrasosa acidulada.-_Para 1 litro de leche agregar 30 gramos de crema obtenida de la descremadora, se hierve al vapor, se enfría y acidula con ácido láctico o jugo de limón. en las mismas proporciones que las anteriores.

Calorias: 800 por litro.

Leche acidulada con agregado de harina.-A 1 litro de leche íntegra o descremada o hipetgrasosa, se le agregan 30 gramos de harina de arroz; se cocina a fuego lento durante 5 
minutos revolviendo continuamente. Se le acidula como las anteriores.

Sopa de babeutre o babeutre con hidtatos de catbono, o teche semidesctemada acidulada con hidratos de catbono.-. Se agregan 100 ó 140 gotas, ó $3.5 \mathrm{cc}$. de ácido láctico, ó 25 a 50 cc. de jugo de limón a 300 gramos de jarabe de dextrino maltosa. Esta mezcla se agrega lentamente batiendo enérgicamente con 700 gramos de leche semidescremada. Si la leche semidescremada acidulada está preparada se le agregan directamente el jarabe de dextrino maltosa.

Calorias: 950 por litro.

Tipo 3 ó Tipo Marriott. Leche integra acidulada con amilodextrina y sacarosa.-En 1 litro de leche se cocina a fuego lento durante 5 minutos, 20 gramos de harina de arroz, se le agregan 50 gramos de azúcar, se enfría y se le agregan $3,5 \mathrm{cc}$. de ácido láctico, ó 25 a $50 \mathrm{cc}$. de jugo de limón. batiendo enérgicamente hasta notar el espesamiento.

Calorías: 980 por litro. 